\title{
elsevier_SPINEE_55913
}

Basic Science

\section{Bilateral pedicle screw fixation provides superior biomechanical stability in transforaminal lumbar interbody fusion: a finite element study}

Divya V. Ambati, MS

Edward K. Wright Jr, PhDa,b,c

Ronald A. Lehman Jr, MD b, c,*

armyspine@yahoo.com

Daniel G. Kang, MD

Scott C. Wagner, $\mathrm{MD}^{\mathrm{c}}$

Anton E. Dmitriev, $\mathrm{PhD}^{\mathrm{a}, \mathrm{b}, \mathrm{c}}$

aThe Henry M. Jackson Foundation for the Advancement of Military Medicine

bUniformed Services University of the Health Sciences

'Department of Orthopaedic Surgery, Walter Reed National Military Medical Center, Bethesda, MD 20889, USA

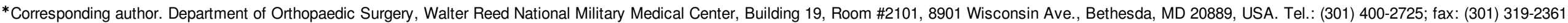

FDA device/drug status: Approved (Interbody cage), (Pedicle screw).

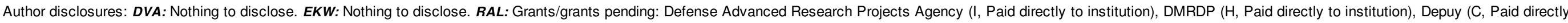
to institution), Sentinel Spine (E). DGK: Nothing to disclose. SCW: Nothing to disclose. AED: Nothing to disclose.

The disclosure key can be found on the Table of Contents and at www. TheSpineJournalOnline.com.

Investigation was performed at the Walter Reed National Military Medical Center, Bethesda, MD, USA.

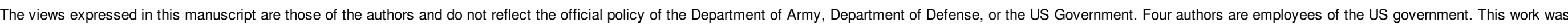
prepared as part of their official duties and, as such, there is no copyright to be transferred.

There are no reproduced copyrighted materials and no funding source for this study. IRB approval with publication clearance was obtained for this study.

The study was supported by a grant from our institution. The authors do not have any relevant disclosures of potential conflicts of interest related to this study.

\section{Abstract}

\section{Background context}

Transforaminal lumbar interbody fusion (TLIF) is increasingly popular for the surgical treatment of degenerative lumbar disease. The optimal construct for segmental stability remains unknown. Purpose

To compare the stability of fusion constructs using standard (C) and crescent-shaped (CC) polyetheretherketone TLIF cages with unilateral (UPS) or bilateral (BPS) posterior instrumentation.

\section{Study design}

Five TLIF fusion constructs were compared using finite element (FE) analysis.

\section{Methods}

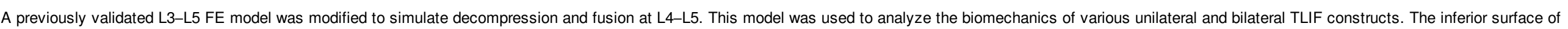

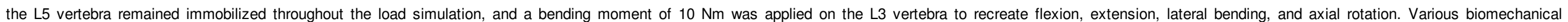

(C) 2014. This manuscript version is made available under the Elsevier user license

http://www.elsevier.com/open-access/userlicense/1.0/ 


\section{elsevier_SPINEE_55913}

parameters were evaluated for intact and implanted models in all loading planes.

Results

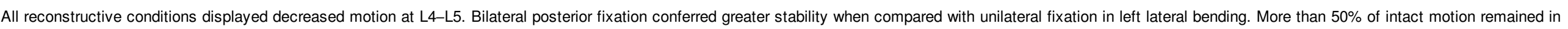

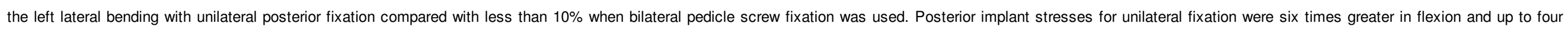

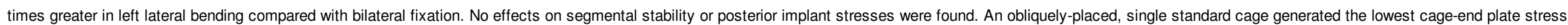
Conclusions

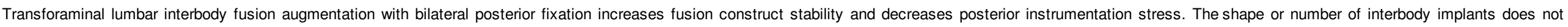

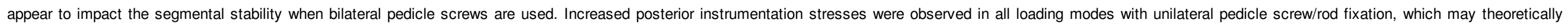
accelerate implant loosening or increase the risk of construct failure.

Keywords: Finite element method; Spine biomechanics; Transforaminal lumbar interbody fusion; Interbody cage; Pedicle screw fixation; Lumbar spine

\section{Introduction}

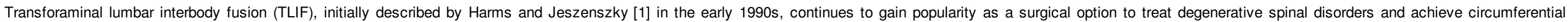

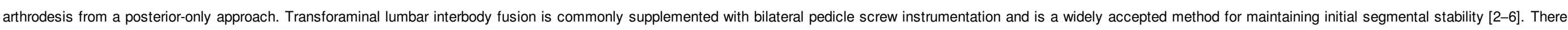

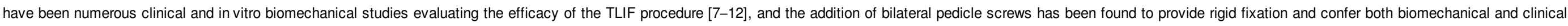
advantages for TLIF constructs [13].

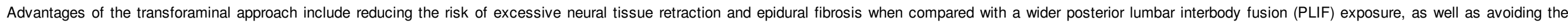

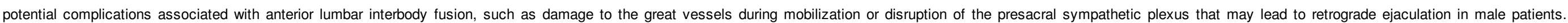

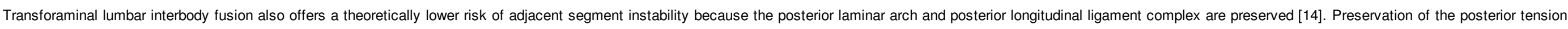
band may also prevent the retropulsion of the interbody device and bone graft into the spinal canal [14].

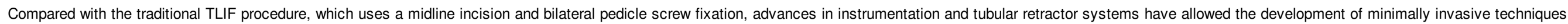

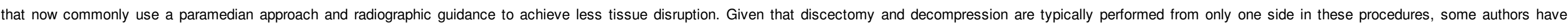

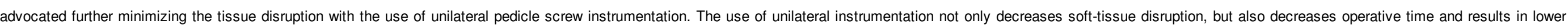

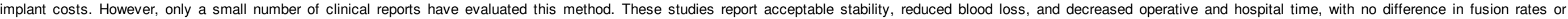

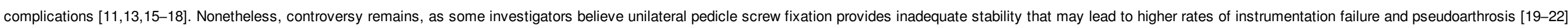

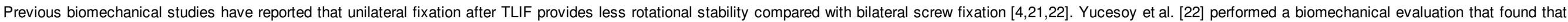

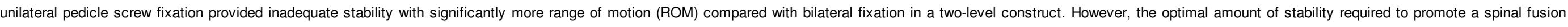

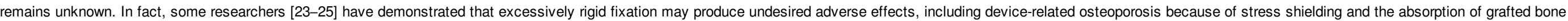
$[26,27]$.

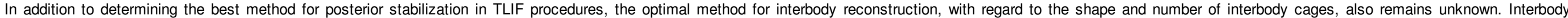

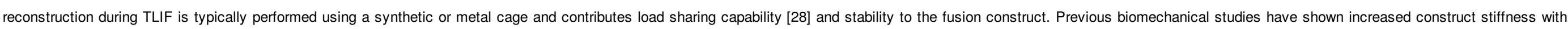

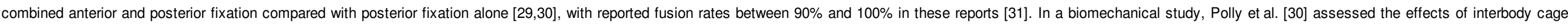

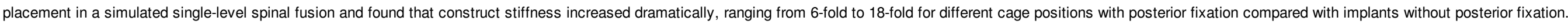

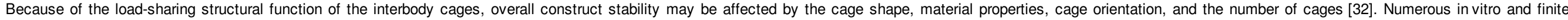

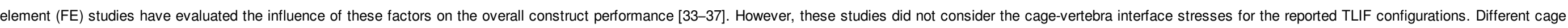




\section{elsevier_SPINEE_55913}

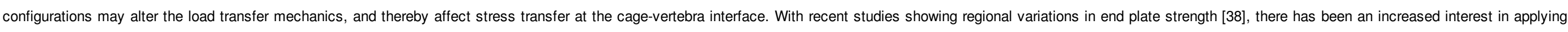

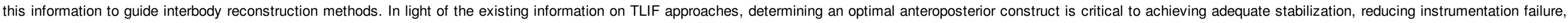

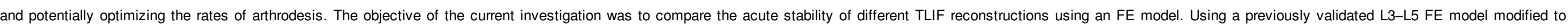

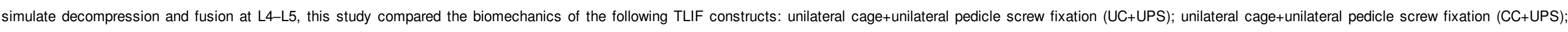

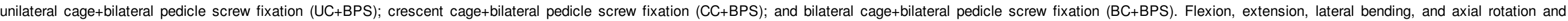
posterior implant and end plate stresses were modeled for each construct.

\section{Methods}

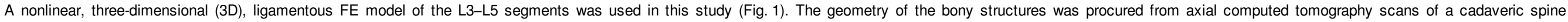

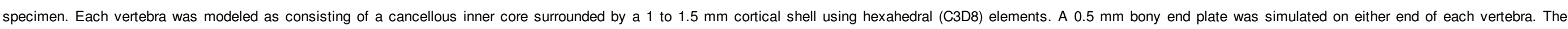

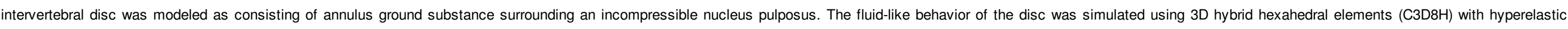

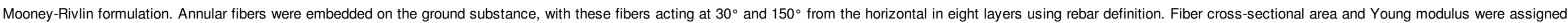

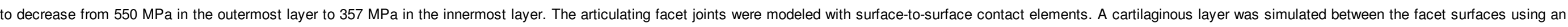

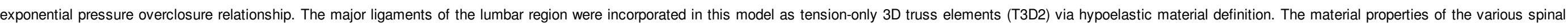
components were derived from the literature as specified in Table. 
elsevier_SPINEE_55913

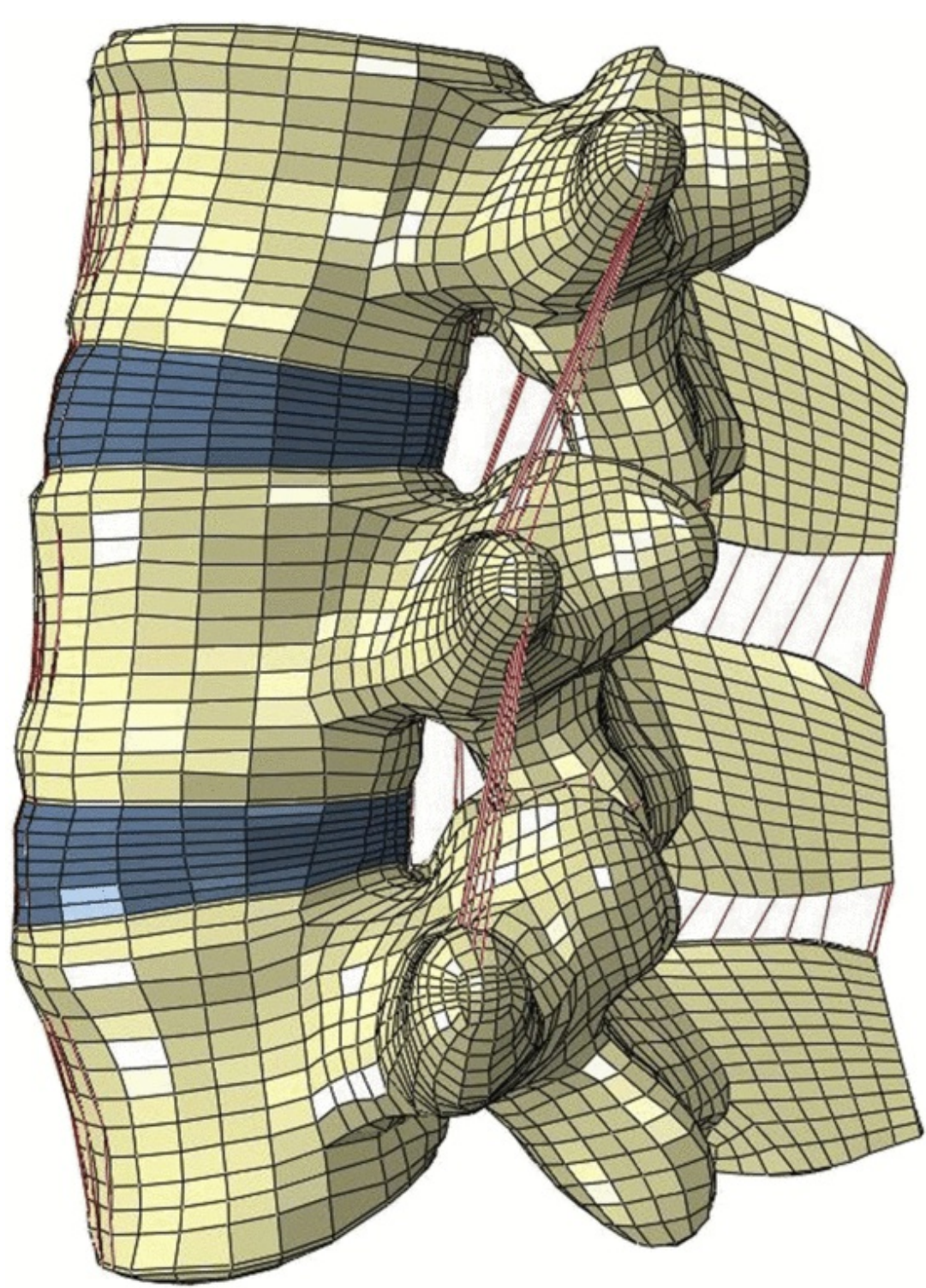

Fig. 1 Finite element model of an L3-L5 spine segment.

Table Material properties of spinal components

\begin{tabular}{|c|c|c|c|}
\hline Element set & Element type & Young modulus (MPa) & Poisson ratio \\
\hline Vertebral cancellous bone & C3D8 & 100 & 0.2 \\
\hline Vertebral cortical bone & C3D8 & 12,000 & 0.3 \\
\hline Posterior bone & C3D8 & 3,500 & 0.25 \\
\hline
\end{tabular}




\section{elsevier_SPINEE_55913}

\begin{tabular}{|c|c|c|c|}
\hline End plates & C3D8 & 1,000 & 0.3 \\
\hline Nucleus pulposus & C3D8H & Hyperelastic (Mooney-Rivlin) $1\left(\mathrm{C}_{1}=0.12, \mathrm{C}_{2}=0.03\right)$ & 0.499 \\
\hline Annulus (ground) & C3D8 & Hyperelastic (Mooney-Rivlin) $1.75\left(\mathrm{C}_{1}=0.2333, \mathrm{C}_{2}=0.0583\right)$ & 0.45 \\
\hline Annulus fibers & Rebar & $357-550$ & 0.3 \\
\hline Facet joint & Contact elements & Exponential pressure overclosure relationship (softened contact) & \\
\hline Ligaments & Tension-only truss elements & & \\
\hline Anterior longitudinal & T3D2 & $12.8-15.0$ & 0.3 \\
\hline Posterior longitudinal & T3D2 & $10.0-20.0$ & 0.3 \\
\hline Capsular & T3D2 & 8.0-20.7 & 0.3 \\
\hline Intertransverse & T3D2 & $10.0-58.7$ & 0.3 \\
\hline Interspinous & T3D2 & $2.8-5.0$ & 0.3 \\
\hline Supraspinous & T3D2 & $2.8-7.0$ & 0.3 \\
\hline Ligamentum flavum & T3D2 & $10.0-15.5$ & 0.3 \\
\hline
\end{tabular}

\section{FE model validation}

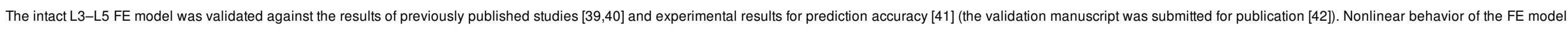
was verified over the entire moment-rotation curve under the conditions of flexion, extension, lateral bending, and axial rotation [42].

\section{Modeling of implants}

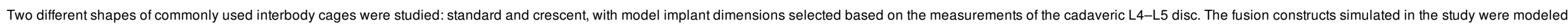

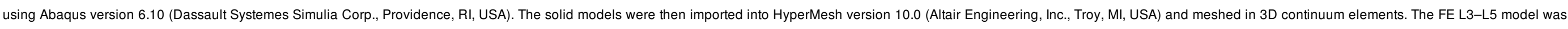

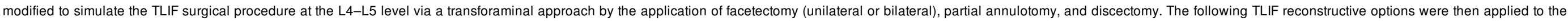

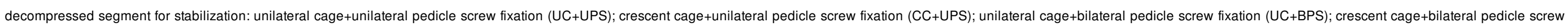
fixation (CC+BPS); and bilateral cage+bilateral pedicle screw fixation (BC+BPS).

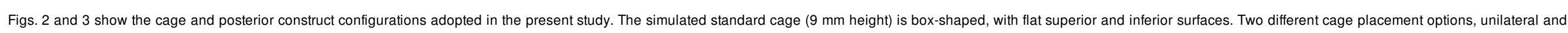

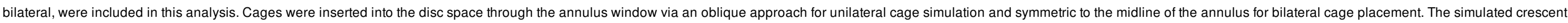

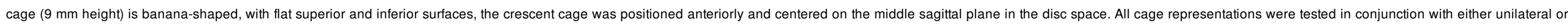

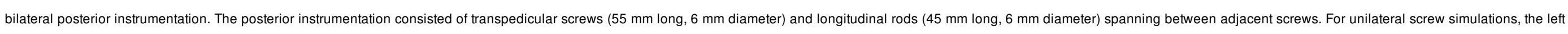
side of the model was assigned to undergo instrumentation. Titanium ( $E=110 \mathrm{GPa})$ and polyetheretherketone ( $\mathrm{E}=3.6 \mathrm{GPa})$ material properties were defined for the posterior instrumentation and interbody cages [43].

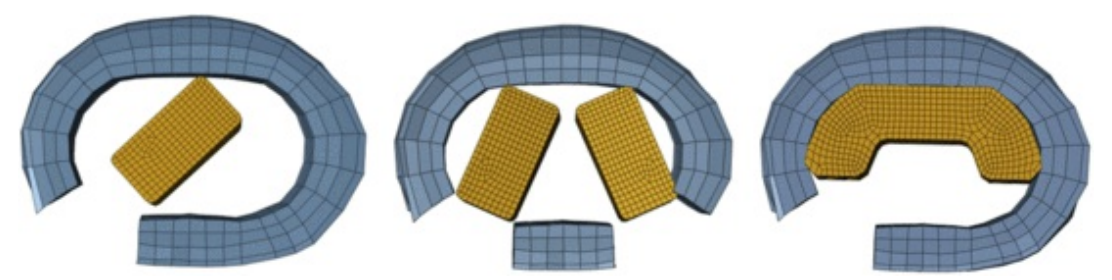

Fig. 2 Transforaminal lumbar interbody fusion cage positions: (Left) unilateral standard cage, (Middle) bilateral standard cages, and (Right) crescent-shaped cage. 

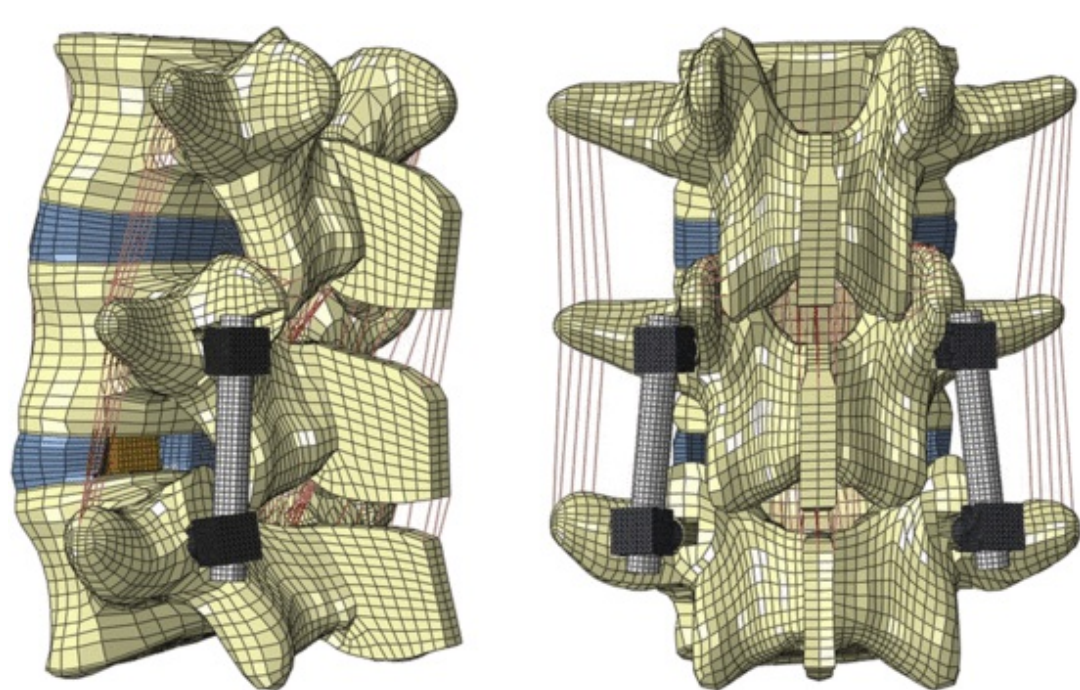

Fig. 3 Posterior instrumentation: (Left) unilateral pedicle screw system and (Right) bilateral pedicle screw system.

\section{Contact definitions}

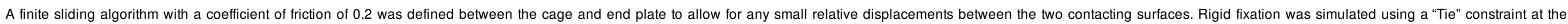
following interfaces: pedicle screw and pedicle/vertebral body and pedicle screw and rod. The pedicle screws were placed such that they engaged about two-thirds of the vertebral body.

\section{Loading and boundary conditions}

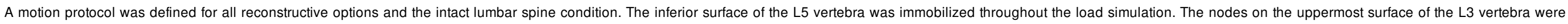

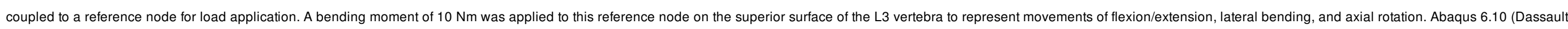

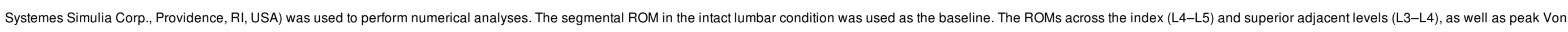
Mises stresses in the posterior instrumentation and L4 inferior end plate, were computed and compared for each model condition.

\section{Results}

\section{Range of motion}

\section{Flexion/extension}

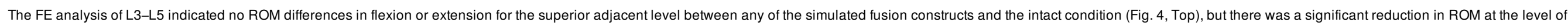

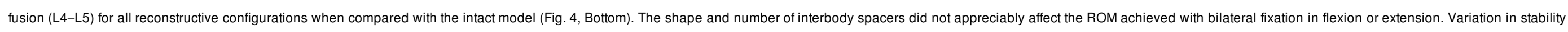
was noted with unilateral posterior fixation when compared with bilateral fixation. 


\section{elsevier_SPINEE_55913}
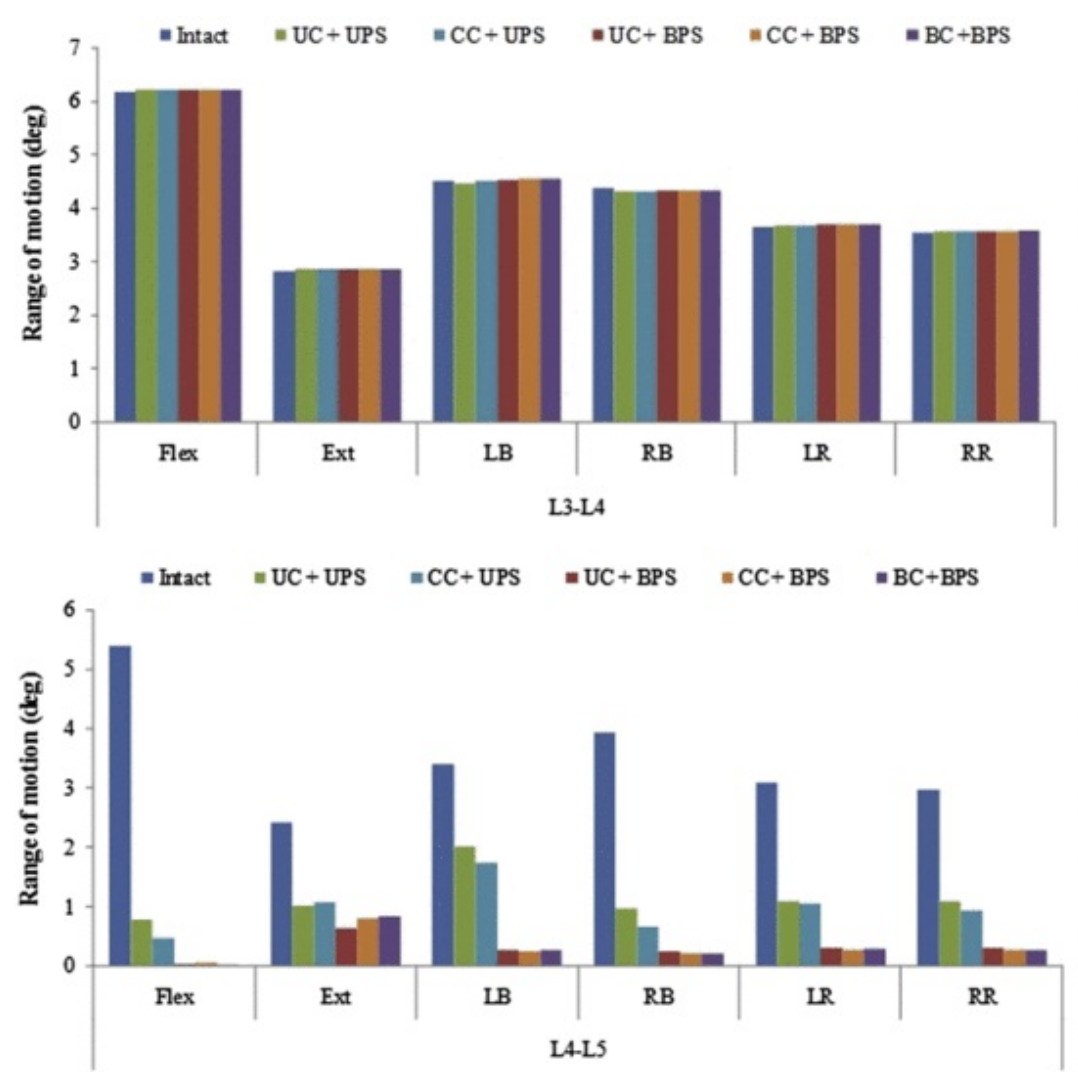

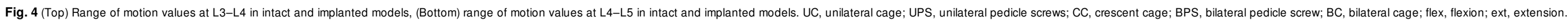

\section{Lateral bending}

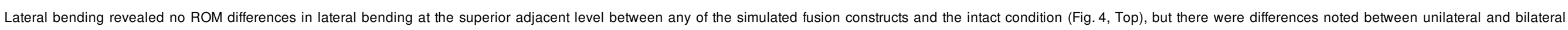

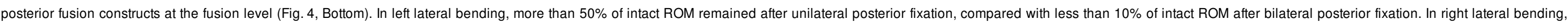

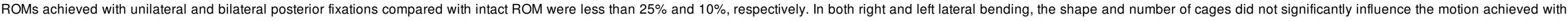
bilateral fixation.

\section{Axial rotation}

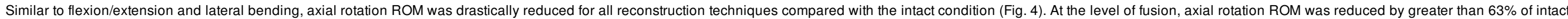

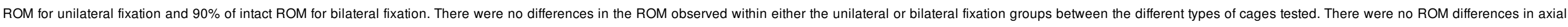
rotation at the superior adjacent level between the intact condition and any of the simulated fusion constructs.

\section{Posterior instrumentation stress analysis}

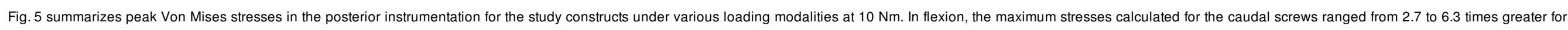

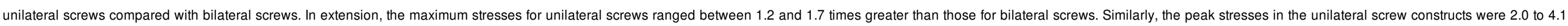

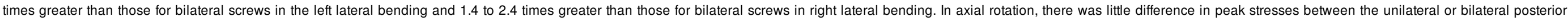




\section{elsevier_SPINEE_55913}

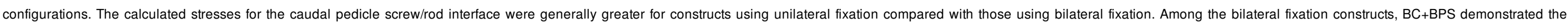
greatest pedicle screw stress, followed by CC+BPS and UC+BPS.

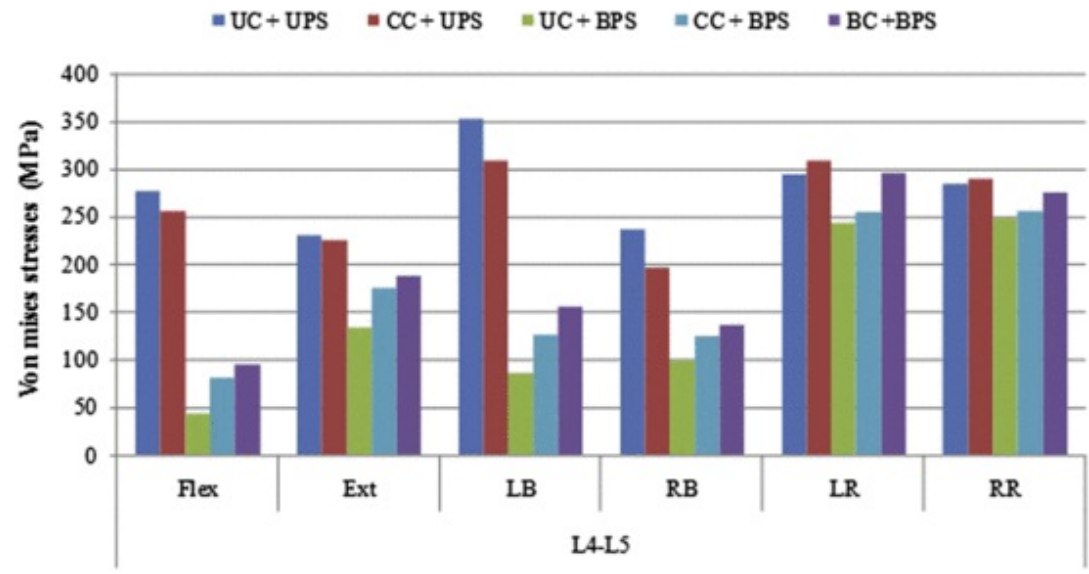

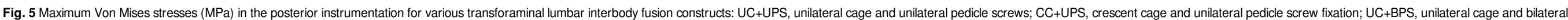

pedicle screw fixation; $\mathrm{CC}+\mathrm{BPS}$, crescent cage and bilateral pedicle screw fixation; $\mathrm{BC}+\mathrm{BPS}$, bilateral cage and bilateral pedicle screw fixation.

\section{L4 inferior end plate stress analysis}

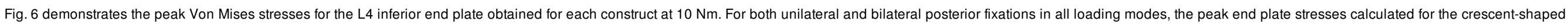

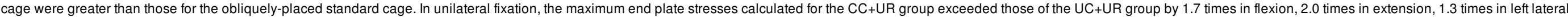

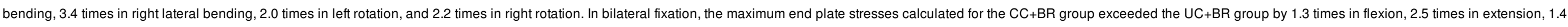

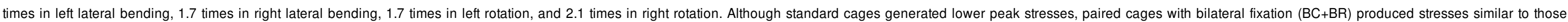

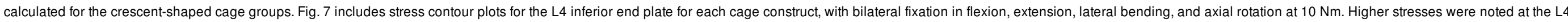

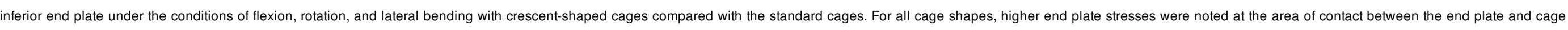
surface.

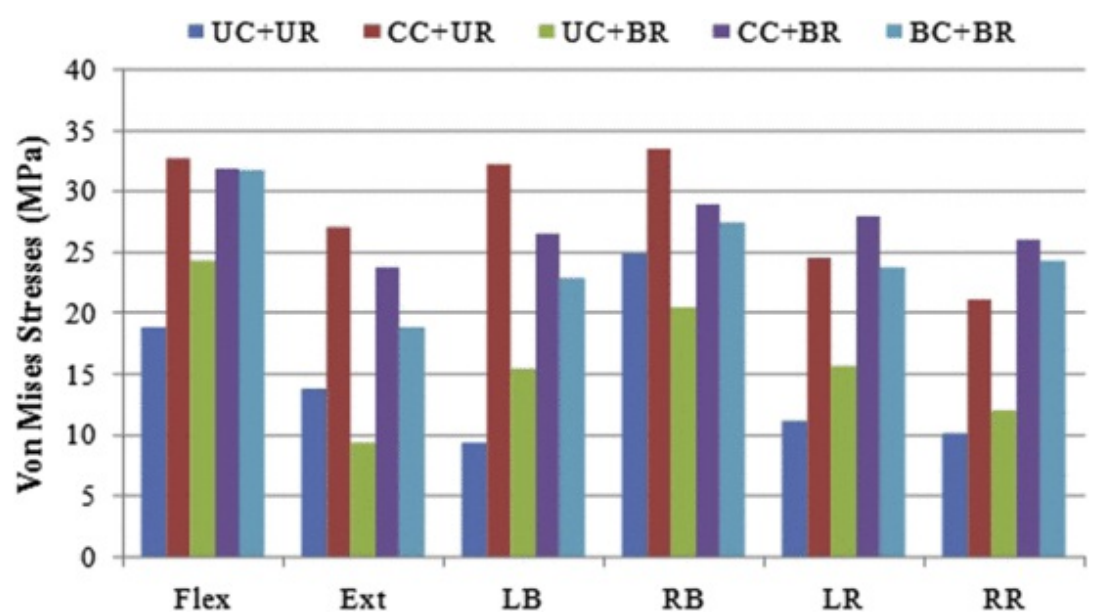

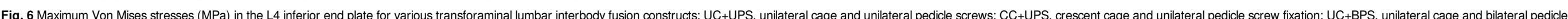




\section{elsevier_SPINEE_55913}

screw fixation; $\mathrm{CC}+\mathrm{BPS}$, crescent cage and bilateral pedicle screw fixation; $\mathrm{BC}+\mathrm{BPS}$, bilateral cage and bilateral pedicle screw fixation.

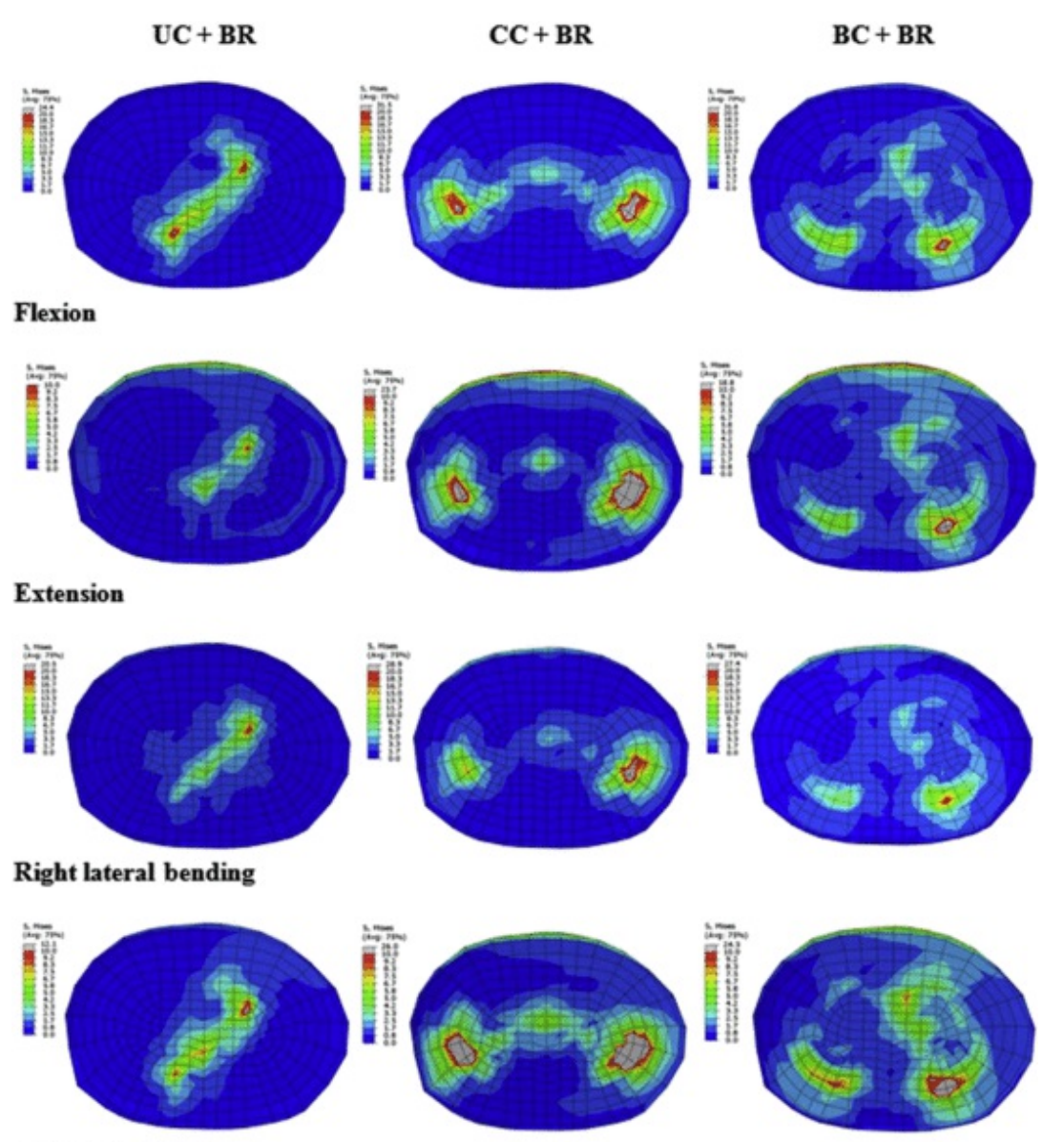

Right axial rotation

Fig. 7 Stress (MPa) plots of single standard, paired standard, and crescent-shaped cages with BR fixation under loading conditions at $10 \mathrm{Nm}$. UC, unilateral cage; CC, crescent cage; BC, bilateral cage; BR, bilateral rod fixation

\section{Discussion}

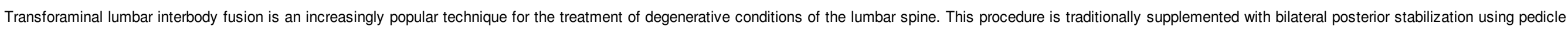

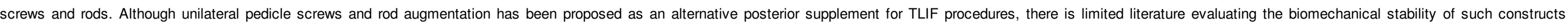

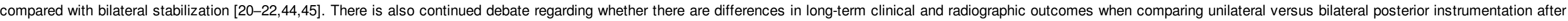

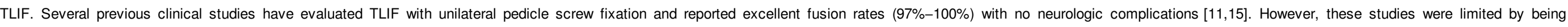

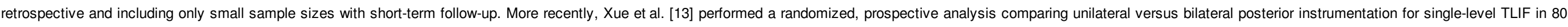

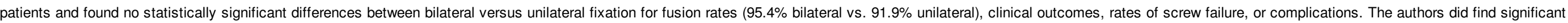

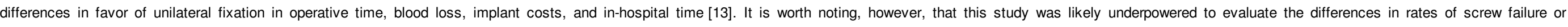

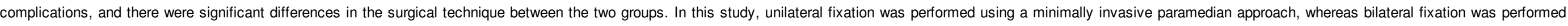

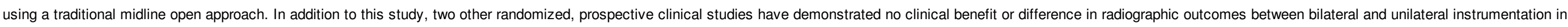




\section{elsevier_SPINEE_55913}

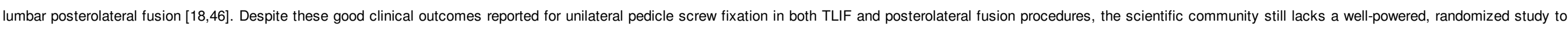
evaluate unilateral versus bilateral posterior fixation in TLIF.

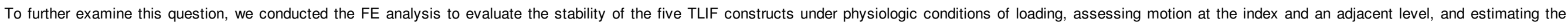

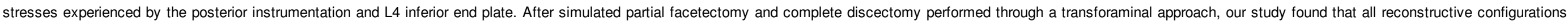

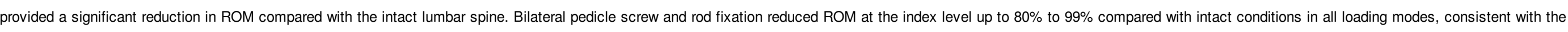

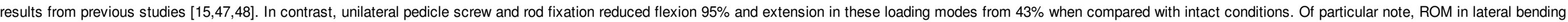

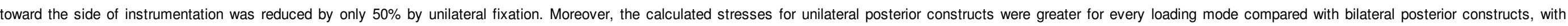

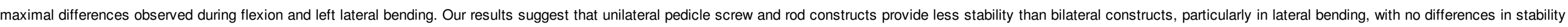

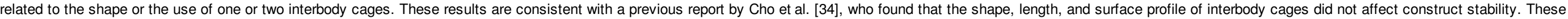
results are concerning because inadequate stabilization, increased motion, and/or elevated implant stresses may theoretically accelerate screw loosening or construct failure under repetitive loading

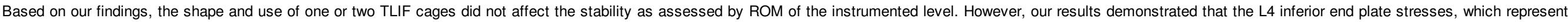

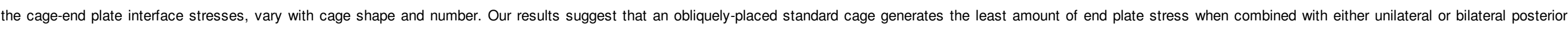

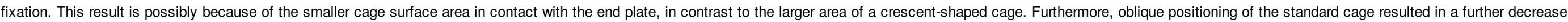

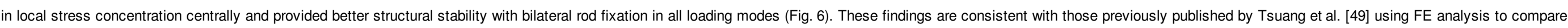

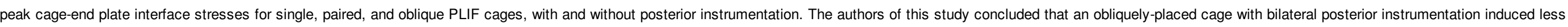

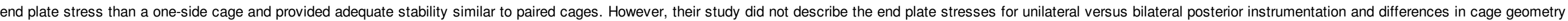

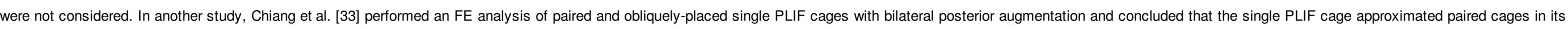
biomechanical stability and generated less stress when compared with paired implants.

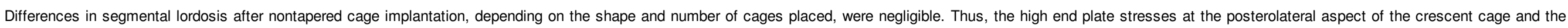

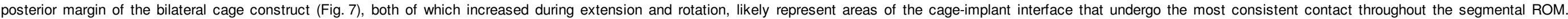

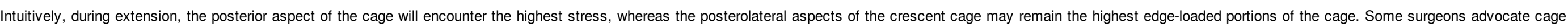

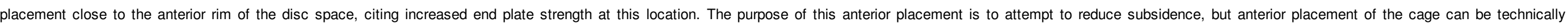

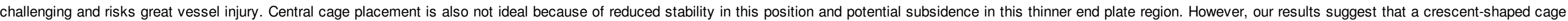

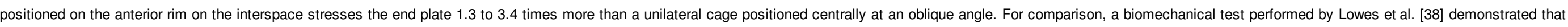

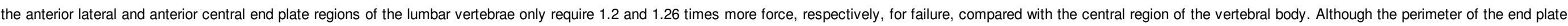

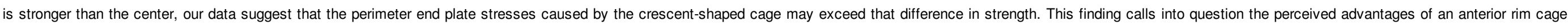

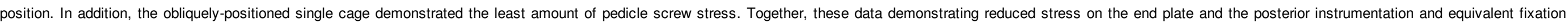
stability suggest that bilateral screws and rods with a unilateral, centrally-placed oblique cage appears to be the advantageous biomechanical construct.

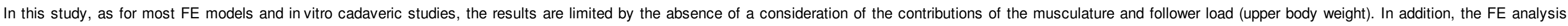

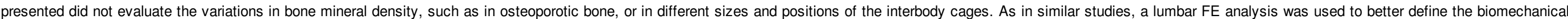

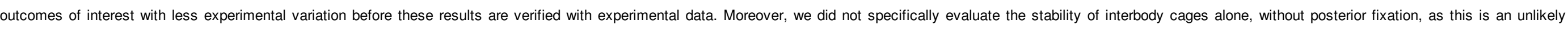

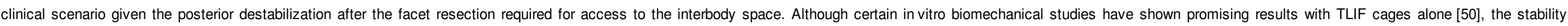
afforded by cages when used as stand-alone devices may not be enough to achieve optimal clinical outcome, especially with dorsal structure violation $[4,36]$ and was therefore, not a question of interest in this study.

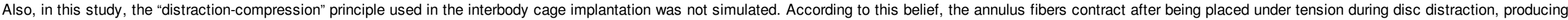

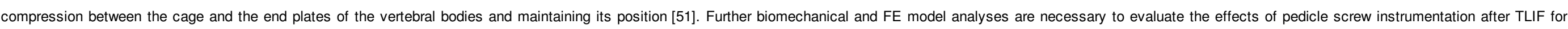

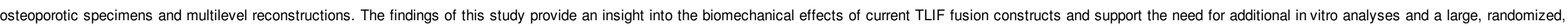
prospective trial comparing these constructs. 


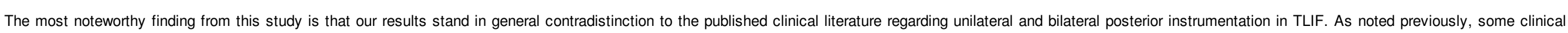

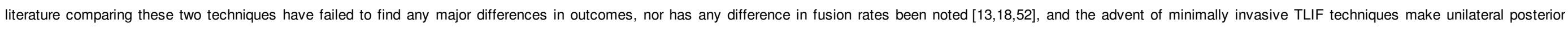

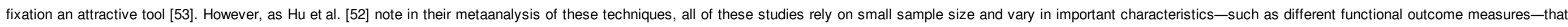

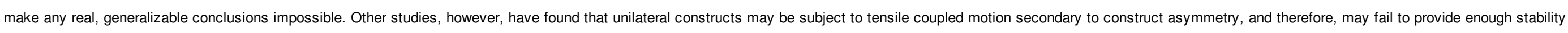

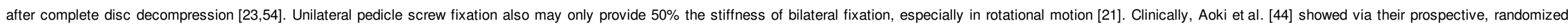

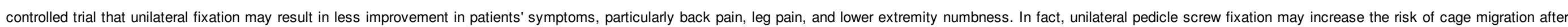

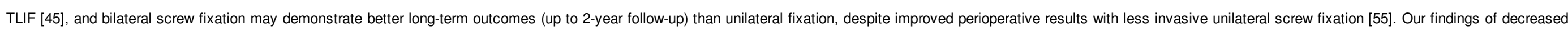
construct stiffness with unilateral fixation may support these clinical data that in some patients, bilateral pedicle screw fixation after TLIF is the most appropriate surgical option.

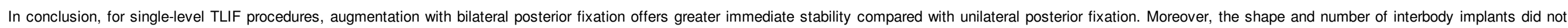

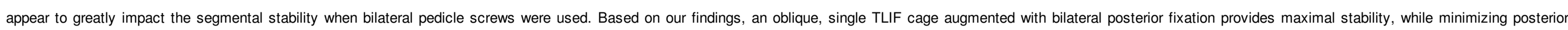

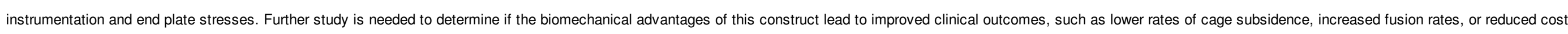
because of fewer hardware failures or complications.

\section{Acknowledgments}

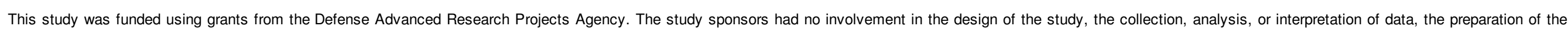
manuscript, or the decision to submit for publication. There are no potential conflicts of interest to report pertaining to this research.

\section{References}

[1]

J.G. Harms and D. Jeszenszky, The unilateral transforaminal approach for posterior lumbar interbody fusion, Oper Orthop Traumatol 10, 1998, 90-102.

[2]

D. Grob, H.J. Scheier, J. Dvorak, H. Siegrist, M. Rubeli and R. Joller, Circumferential fusion of the lumbar and lumbosacral spine, Arch Orthop Trauma Surg 111, $1991,20-25$.

[3]

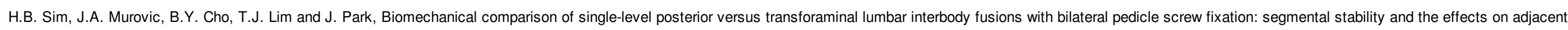
motion segments, J Neurosurg Spine 12, 2010, 700-708.

[4]

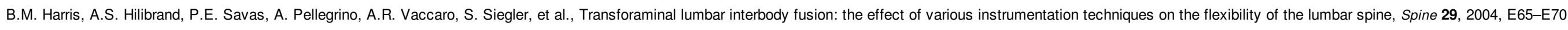

[5]

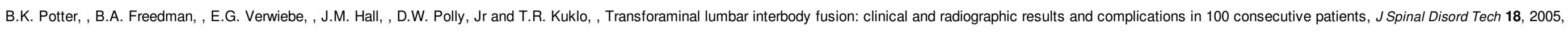
337-346.

[6]

Y.X. Xiao, Q.X. Chen and F.C. Li, Unilateral transforaminal lumbar interbody fusion: a review of the technique, indications and graft materials, J Int Med Res 37, $2009,908-917$.

[7]

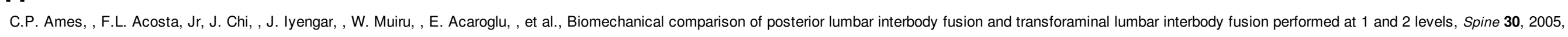
E562-E566. 


\section{elsevier_SPINEE_55913}

[8]

C.A. Chastain, J.C. Eck, S.D. Hodges, S.C. Humphreys and P. Levi, Transforaminal lumbar interbody fusion: a retrospective study of long-term pain relief and fusion outcomes, Orthopedics 30, 2007 , 389-392.

[9]

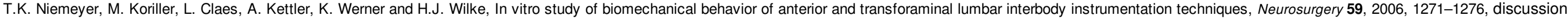
$1276-7$

[10]

W.S. Rosenberg and P.V. Mummaneni, Transforaminal lumbar interbody fusion: technique, complications, and early results, Neurosurgery 48, 2001, 569-574, discussion 574-5.

[11]

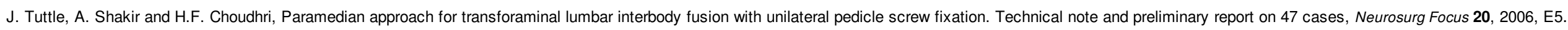

\section{[12]}

D.L. Yan, F.X. Pei, J. Li and C.L. Soo, Comparative study of PILF and TLIF treatment in adult degenerative spondylolisthesis, Eur Spine J 17, 2008, 1311-1316.

[13]

H. Xue, Y. Tu and M. Cai, Comparison of unilateral versus bilateral instrumented transforaminal lumbar interbody fusion in degenerative lumbar diseases, Spine J 12, $2012,209-215$.

[14]

T.G. Lowe, A.D. Tahernia, M.F. O'Brien and D.A. Smith, Unilateral transforaminal posterior lumbar interbody fusion (TLIF): indications, technique, and 2-year results, J Spinal Disord Tech 15, 2002, 31-38.

[15]

W.F. Beringer and J.P. Mobasser, Unilateral pedicle screw instrumentation for minimally invasive transforaminal lumbar interbody fusion, Neurosurg Focus 20, 2006 , E4.

[16]

H. Deutsch, and M.J. Musacchio, Jr, Minimally invasive transforaminal lumbar interbody fusion with unilateral pedicle screw fixation, Neurosurg Focus 20,2006, E10.

[17]

M.B. Kabins, J.N. Weinstein, K.F. Spratt, E.M. Found, V.K. Goel, J. Woody, et al., Isolated L4-L5 fusions using the variable screw placement system: unilateral versus bilateral, J Spinal Disord 5, 1992, 39-49.

[18]

K.S. Suk, H.M. Lee, N.H. Kim and J.W. Ha, Unilateral versus bilateral pedicle screw fixation in lumbar spinal fusion, Spine 25, 2000, $1843-1847$.

[19]

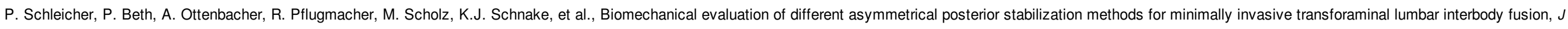
Neurosurg Spine 9, 2008, 363-371.

[20]

H.H. Chen, H.H. Cheung, W.K. Wang, A. Li and K.C. Li, Biomechanical analysis of unilateral fixation with interbody cages, Spine 30, 2005, E92-E96.

[21]

A.V. Slucky, D.S. Brodke, K.N. Bachus, J.A. Droge and J.T. Braun, Less invasive posterior fixation method following transforaminal lumbar interbody fusion: a biomechanical analysis, Spine J6, 2006, 78-85.

[22]

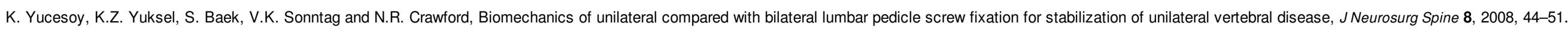




\section{elsevier_SPINEE_55913}

V.K. Goel, T.H. Lim, J. Gwon, J.Y. Chen, J.M. Winterbottom, J.B. Park, et al., Effects of rigidity of an internal fixation device. A comprehensive biomechanical investigation, Spine 16 (3 Suppl), 1991 , S155-S161.

[24]

P.C. McAfee, I.D. Farey, C.E. Sutterlin, K.R. Gurr, K.E. Warden and B.W. Cunningham, 1989 Volvo Award in basic science. Device-related osteoporosis with spinal instrumentation, Spine 14, 1989, 919-926.

[25]

P.C. McAfee, I.D. Farey, C.E. Sutterlin, K.R. Gurr, K.E. Warden and B.W. Cunningham, The effect of spinal implant rigidity on vertebral bone density. A canine model, Spine 16 (6 Suppl), 1991 , S190-S197.

[26]

H. Nagata, M.J. Schendel, E.E. Transfeldt and J.L. Lewis, The effects of immobilization of long segments of the spine on the adjacent and distal facet force and lumbosacral motion, Spine 18, 1993, 2471-2479.

[27]

P. Park, H.J. Garton, V.C. Gala, J.T. Hoff and J.E. McGillicuddy, Adjacent segment disease after lumbar or lumbosacral fusion: review of the literature, Spine 29, 2004, $1938-1944$.

[28]

A. Polikeit, S.J. Ferguson, L.P. Nolte and T.E. Orr, Factors influencing stresses in the lumbar spine after the insertion of intervertebral cages: finite element analysis, Eur Spine $J$ 12, 2003 , 413-420.

[29]

B.W. Cunningham, I. Oda and C.J. Haggerty, Biomechanical effects of posterior rod diameter and anterior column reconstruction on multisegmental spinal stability, Trans Orthop Res Soc 24, 1999.

[30]

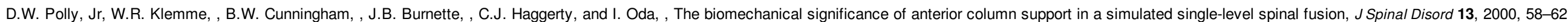

[31]

T.A. Zdeblick and F.M. Phillips, Interbody cage devices, Spine 28 (15 Suppl), 2003, S2-S7.

[32]

A. Kettler, H.J. Wilke, R. Dietl, M. Krammer, C. Lumenta and L. Claes, Stabilizing effect of posterior lumbar interbody fusion cages before and after cyclic loading, J Neurosurg 92 (1 Suppl), $2000,87-92$.

[33]

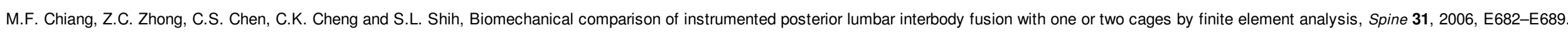

[34]

W. Cho, C. Wu, A.A. Mehbod and E.E. Transfeldt, Comparison of cage designs for transforaminal lumbar interbody fusion: a biomechanical study, Clin Biomech (Bristol, Avon) 23, $2008,979-985$.

[35]

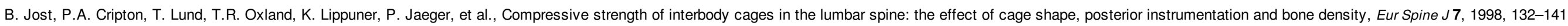

[36]

S.T. Wang, V.K. Goel, C.Y. Fu, S. Kubo, W. Choi, C.L. Liu, et al., Posterior instrumentation reduces differences in spine stability as a result of different cage orientations: an in vitro study, Spine 30, $2005,62-67$.

[37]

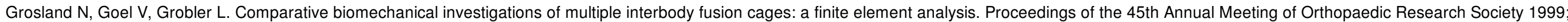
Anaheim, CA.

[38]

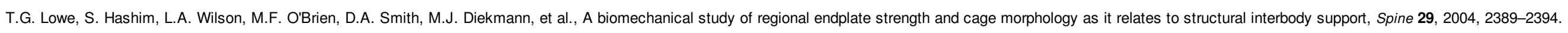




\section{elsevier_SPINEE_55913}

[39]

C.S. Chen, C.K. Cheng, C.L. Liu and W.H. Lo, Stress analysis of the disc adjacent to interbody fusion in lumbar spine, Med Eng Phys 23, 2001, 483-491.

[40]

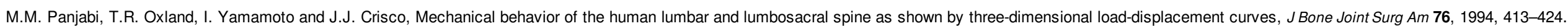

[41]

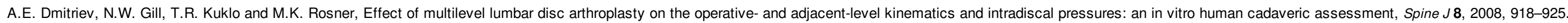

[42]

D.V. Ambati, J. Wright, K. Edward, J. Lehman, A. Ronald and A.E. Dmitriev, A finite-element model to accurately predict biomechanical behavior of the human lumbosacral spine, Spine J 2013.

[43]

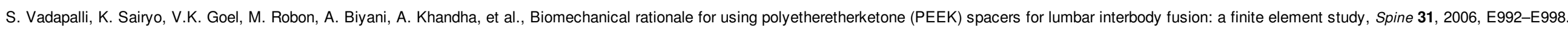

[44]

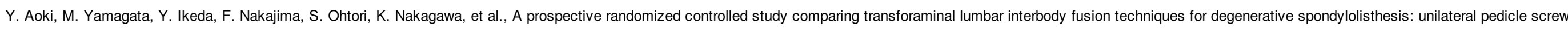
and 1 cage versus bilateral pedicle screws and 2 cages, J Neurosurg Spine 17, 2012, 153-159.

[45]

J.W. Duncan and R.A. Bailey, An analysis of fusion cage migration in unilateral and bilateral fixation with transforaminal lumbar interbody fusion, Eur Spine $J$ 22, $2013,439-445$.

[46]

M. Fernandez-Fairen, P. Sala, H. Ramirez and J. Gil, A prospective randomized study of unilateral versus bilateral instrumented posterolateral lumbar fusion in degenerative spondylolisthesis, Spine 32, 2007 , 395-401.

[47]

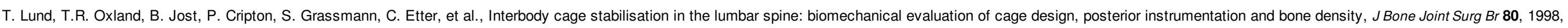
351-359.

[48]

T.R. Oxland and T. Lund, Biomechanics of stand-alone cages and cages in combination with posterior fixation: a literature review, Eur Spine J 9 (1 Suppl), 2000 , S95-S101.

[49]

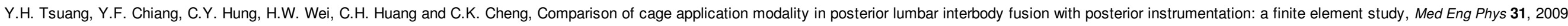
$565-570$.

[50]

A. Kettler, W. Schmoelz, E. Kast, M. Gottwald, L. Claes and H.J. Wilke, In vitro stabilizing effect of a transforaminal compared with two posterior lumbar interbody fusion cages, Spine 30, 2005, E665-E670.

[51]

G.W. Bagby, Arthrodesis by the distraction-compression method using a stainless steel implant, Orthopedics 11, 1988, 931-934.

[52]

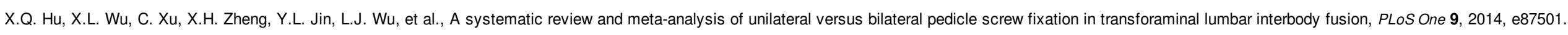

[53]

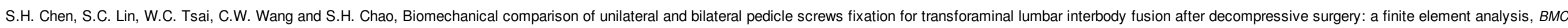




\section{elsevier_SPINEE_55913}

Musculoskelet Disord 13, 2012, 72.

[54]

V.K. Goel, M.M. Panjabi, A.G. Patwardhan, A.P. Dooris and H. Serhan, Test protocols for evaluation of spinal implants, J Bone Joint Surg Am 88 (2 Suppl), $2006,103-109$.

[55]

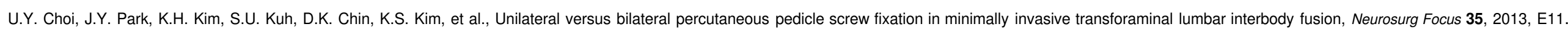

